\section{(6) OPEN ACCESS}

\title{
Do television and electronic games predict children's psychosocial adjustment? Longitudinal research using the UK Millennium Cohort Study
}

\author{
Alison Parkes, Helen Sweeting, Daniel Wight, Marion Henderson
}

Medical Research Council/ CSO Social and Public Health Sciences Unit, University of Glasgow, Glasgow, UK

\section{Correspondence to} Dr Alison Parkes, MRC/CSO Social and Public Health Sciences Unit, University of Glasgow, 4 Lilybank Gardens, Glasgow G12 8RZ, UK; Alison-p@sphsu.mrc.ac.uk

Received 7 December 2011 Revised 15 October 2012 Accepted 7 December 2012 Published Online First 25 March 2013

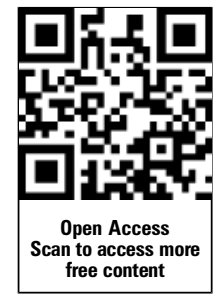

To cite: Parkes $A$, Sweeting $H$, Wight $D$, et al. Arch Dis Child

2013;98:341-348.

\begin{abstract}
Background Screen entertainment for young children has been associated with several aspects of psychosocial adjustment. Most research is from North America and focuses on television. Few longitudinal studies have compared the effects of TV and electronic games, or have investigated gender differences.
\end{abstract}

Purpose To explore how time watching TV and playing electronic games at age 5 years each predicts change in psychosocial adjustment in a representative sample of 7 year-olds from the UK.

Methods Typical daily hours viewing television and playing electronic games at age 5 years were reported by mothers of 11014 children from the UK Millennium Cohort Study. Conduct problems, emotional symptoms, peer relationship problems, hyperactivity/inattention and prosocial behaviour were reported by mothers using the Strengths and Difficulties Questionnaire. Change in adjustment from age 5 years to 7 years was regressed on screen exposures; adjusting for family characteristics and functioning, and child characteristics.

Results Watching TV for $3 \mathrm{~h}$ or more at 5 years predicted a 0.13 point increase $(95 \% \mathrm{Cl} 0.03$ to 0.24$)$ in conduct problems by 7 years, compared with watching for under an hour, but playing electronic games was not associated with conduct problems. No associations were found between either type of screen time and emotional symptoms, hyperactivity/inattention, peer relationship problems or prosocial behaviour. There was no evidence of gender differences in the effect of screen time.

Conclusions TV but not electronic games predicted a small increase in conduct problems. Screen time did not predict other aspects of psychosocial adjustment. Further work is required to establish causal mechanisms.

\section{INTRODUCTION}

Television and electronic games are prominent features of children's home environments in many high-income countries. However, children's heavy screen time has been linked with obesity, sleep problems, lower cognitive skills and poor academic adjustment. ${ }^{1-3}$ High screen time may also predict behavioural and emotional problems in children, including aggression, ${ }^{45}$ anxiety and depression, ${ }^{5-7}$ victimisation, ${ }^{3}$ social isolation, ${ }^{8}$ reduced prosocial behaviour ${ }^{49}$ and attentional problems. ${ }^{4} 1011$

Heavy screen time might impair children's mental health in various ways, particularly if it involves viewing material not primarily designed for children and/or with less adult supervision. Screen entertainment's rapid pace, frequent changes of image and capacity to excite may shorten concentration $\operatorname{span}^{12}$ and reduce time

\section{What is already known on this topic}

- High screen time has been linked with behavioural and emotional problems in children, although findings have not all been consistent.

- Most longitudinal studies have focused on television and almost all have been conducted in North America.

- Few studies have examined TV and electronic games separately to see whether they have similar effects.

\section{What this study adds}

- Watching TV for $3 \mathrm{~h}$ or more daily at 5 years predicted increasing conduct problems between the ages of 5 years and 7 years.

- No effects of TV at 5 years were found on hyperactivity/inattention, emotional symptoms, peer relationship problems or prosocial behaviour.

- Playing electronic games at 5 years was not associated with increased risk of problems.

spent on other key developmental activities, including interpersonal interactions. ${ }^{13}$ Violent content may 'prime' children for aggression and prompt them to imitate aggressive behaviour they have just seen. Longer term effects may include desensitisation to violence, and development of attitudes supporting the use of aggression. ${ }^{5}{ }^{14}$ Violent content may also increase children's perceptions that the world is a 'scary place', resulting in trauma symptoms including depression and anxiety. ${ }^{6}$

It is thought that many psychological processes associated with exposure to TV and electronic games are similar, particularly those regarding the development of attentional problems and aggressive behaviour. ${ }^{15}$ However, games may have more powerful effects due to active user engagement, identification with characters and repeated rehearsal and reinforcement. ${ }^{16}$ Gaming's interactive and absorbing qualities may substitute for interpersonal relationships and increase social isolation. ${ }^{17}$ Such isolation may provoke anxiety and depression ${ }^{18}$ or, if coupled with reduced empathy (from exposure to violent games) may depress prosocial 
behaviour. ${ }^{19}$ Few studies have examined young children's use of electronic games, although a recent study found negative effects of television and video game exposure on attentional problems in middle childhood. ${ }^{11}$

There are, however, a number of alternative explanations for associations observed between screen time and psychosocial adjustment. Family circumstances and functioning may underpin variation in children's screen time and poor adjustment. ${ }^{20}$ Links between screen time and mental health may be indirect, rather than direct, for example, via increased sedentary behaviour, sleeping difficulties and language development. ${ }^{21-23}$ Lastly, the child's own temperament may predict screen time. ${ }^{24}$ Longitudinal studies of early screen exposure on children's mental health must take account of these alternative possibilities, in order to demonstrate direct associations between screen time and children's mental health.

More research would be valuable to supplement existing longitudinal studies on young children that do allow for a range of confounders. $^{3} 9102526$ All but one ${ }^{9}$ of these studies come from North America and findings are inconsistent with regard to attentional problems ${ }^{4} 1025$ and aggression. ${ }^{326}$ There are also limitations in scope. Only two examined prosocial behaviour. ${ }^{9}{ }^{26}$ Only one recent study has distinguished between TV and video game exposure, ${ }^{11}$ but did not allow for many potential confounders. None of these studies examined gender differences, although psychosocial adjustment and screen use are patterned by gender. ${ }^{27-31}$

This study explores associations between children's screen exposure at age 5 years and change in adjustment from ages 5 years to 7 years, using a nationally representative sample from the UK. In the UK, watching television, videos or DVDs and electronic gaming using a games console or computer are the most common 'media activities' for 5-7-year-olds, and average 2011 weekly exposure times were $15 \mathrm{~h}$ TV compared with $6 \frac{1}{2}$ h gaming. ${ }^{32}$ We explore TV/video/DVD watching separately from gaming, to see whether passive and interactive forms of screen time have similar or different effects. We examine gender differences and take account of a wide range of confounders, to assess whether screen exposure may be an independent predictor of children's mental health.

\section{METHODS}

\section{Participants}

The Millennium Cohort Study is a prospective study of UK children born between September 2000 and January 2002 eligible for child benefit (a universal benefit). ${ }^{33-37}$ A stratified clustered sampling design over-represented children from disadvantaged areas, ethnic minority groups and from Wales, Scotland and northern Ireland. Families were first surveyed at 9 months, when 18818 children from 18552 families were contacted (72\% of eligible cases). Families were contacted again when children were aged 3 years, 5 years and 7 years. Parents were given the opportunity to opt out, and consent was sought and obtained at each contact. The survey received ethical approval from the South-West, London, Northern and Yorkshire Multi-centre Research Ethics Committees of the NHS.

\section{Study sample}

At age 7 years, 13857 children remained in the survey. Survey attrition was higher in disadvantaged families, where respondents had moved home and where consent to data linkage was not given. This study was restricted to singleton cases $(\mathrm{N}=13$ 681), where the child's natural mother provided information at all four contacts $(\mathrm{N}=11014)$. Sample characteristics are shown in table 1.

\section{Outcome measures}

Psychosocial adjustment was reported by mothers at ages 5 years and 7 years using the Strengths and Difficulties Questionnaire (SDQ), ${ }^{38}$ a widely-used survey instrument with high validity and reliability. The SDQ contains five scales, measuring conduct problems, emotional symptoms, inattention/ hyperactivity, peer relationship problems and prosocial behaviour. Each scale contains five items scored from 0 to 2 , giving a scale range of 0 to 10 . Change scores were calculated by subtracting age 5 years from age 7 years scores, to give measures ranging from -10 to +10 .

\section{Screen time}

Television/video/DVD viewing (referred to as 'TV' here) and playing computer or other electronic games (referred to as 'electronic games') were reported by mothers when children were age 5 years. For both types of screen time, typical weekday term-time hours of exposure outside school were measured on a 6-point scale: none, $<1 \mathrm{~h}, 1-<3 \mathrm{~h}, 3-<5 \mathrm{~h}, 5-<7 \mathrm{~h}, 7 \mathrm{~h}$ or more.

\section{Covariates}

Selection of covariates was guided by the literature on associations with adjustment and screen use. Sociodemographic factors and maternal characteristics (measured when child aged 1 year

Table 1 Selected sample characteristics, Millennium Cohort Study

\begin{tabular}{|c|c|c|}
\hline & $\%$ & $\begin{array}{l}\mathrm{N} \\
\text { unweighted }\end{array}$ \\
\hline \multicolumn{3}{|l|}{ Gender of child } \\
\hline Female & 51.1 & 5576 \\
\hline Male & 48.9 & 5438 \\
\hline \multicolumn{3}{|l|}{ Maternal ethnic group } \\
\hline White & 89.9 & 9724 \\
\hline Minority & 10.1 & 1269 \\
\hline \multicolumn{3}{|l|}{ Maternal highest education level, child aged 1 year* } \\
\hline NVQ 1 & 9.9 & 859 \\
\hline NVQ 2 & 35.5 & 3203 \\
\hline NVQ 3 & 16.9 & 1656 \\
\hline NVQ 4 & 33.8 & 3349 \\
\hline NVQ 5 & 3.9 & 421 \\
\hline \multicolumn{3}{|l|}{ Maternal employment, child aged 5 years } \\
\hline Not in work & 58.4 & 6615 \\
\hline In work & 41.6 & 4934 \\
\hline \multicolumn{3}{|l|}{ Household equivalised income, child aged 1 year } \\
\hline $\begin{array}{l}\text { Below } 60 \% \text { of The Organisation for Economic } \\
\text { Co-operation and Development (OECD) median poverty } \\
\text { indicator }\end{array}$ & 71.6 & 7282 \\
\hline Above $60 \%$ of OECD median poverty indicator & 28.4 & 2926 \\
\hline \multicolumn{3}{|l|}{ Biological father in household, child aged 5 years } \\
\hline Present & 78.3 & 8781 \\
\hline Absent & 21.7 & 2233 \\
\hline \multicolumn{3}{|l|}{ Siblings, child age 5 years } \\
\hline None & 16.0 & 1736 \\
\hline One & 49.1 & 5322 \\
\hline Two & 23.4 & 2611 \\
\hline Three or more & 11.4 & 1325 \\
\hline
\end{tabular}

*NVQ (National Vocational qualification) level represents highest academic or vocational educational qualification obtained. In terms of academic qualifications, the two highest levels are level 4 (corresponding to a first university degree or a diploma in higher education) and level 5 (corresponding to a higher degree). Degree-level professional, nursing or other medical vocational qualifications are treated as equivalent to level 4 . OECD, The Organisation for Economic Co-operation and Development. 
Table 2 Children's exposure to TV/videos/DVDs and electronic games at age 5 years

\begin{tabular}{|c|c|c|c|c|c|c|}
\hline & \multicolumn{2}{|l|}{ Boys } & \multicolumn{2}{|l|}{ Girls } & \multicolumn{2}{|c|}{ Total } \\
\hline & $\%$ & $\mathbf{n}$ & $\%$ & $\mathbf{n}$ & $\%$ & $\mathrm{n}$ \\
\hline \multicolumn{7}{|c|}{ Television/video/DVD use (term time weekday) at age 5 years* } \\
\hline None & 1.5 & 90 & 1.9 & 104 & 1.7 & 194 \\
\hline Less than an hour & 17.5 & 992 & 20.5 & 1138 & 18.9 & 2130 \\
\hline $1 \mathrm{~h}$ to less than $3 \mathrm{~h}$ & 65.0 & 3597 & 63.9 & 3464 & 64.5 & 7061 \\
\hline $3 \mathrm{~h}$ to less than $5 \mathrm{~h}$ & 10.3 & 579 & 9.0 & 476 & 9.7 & 1055 \\
\hline $5 \mathrm{~h}$ to less than $7 \mathrm{~h}$ & 2.3 & 127 & 1.9 & 101 & 2.1 & 228 \\
\hline $7 \mathrm{~h}$ or more & 3.3 & 179 & 2.9 & 139 & 3.1 & 318 \\
\hline \multicolumn{7}{|c|}{ Computer/electronic games use (term time weekday) at age 5 years $\dagger$} \\
\hline None & 28.3 & 1538 & 36.4 & 1974 & 32.3 & 3512 \\
\hline Less than an hour & 43.7 & 2457 & 47.1 & 2533 & 45.3 & 4990 \\
\hline $1 \mathrm{~h}$ to less than $3 \mathrm{~h}$ & 24.1 & 1368 & 14.7 & 813 & 19.5 & 2181 \\
\hline $3 \mathrm{~h}$ to less than $5 \mathrm{~h}$ & 2.3 & 119 & 1.2 & 67 & 1.8 & 186 \\
\hline $5 \mathrm{~h}$ to less than $7 \mathrm{~h}$ & 0.6 & 38 & 0.3 & 14 & 0.5 & 52 \\
\hline $7 \mathrm{~h}$ or more & 0.9 & 43 & 0.4 & 22 & 0.7 & 65 \\
\hline
\end{tabular}

Notes: percentages allow for survey design and weights.

${ }^{*}$ Gender difference in TV viewing $\mathrm{p}=0.003$.

tGender difference in electronic games $p<0.001$.

unless otherwise stated) included mother's ethnicity, maternal education, equivalised household income, maternal employment (child aged 5 years), maternal physical and mental health using the SF-8 scale s9 $^{39}$ and family composition (biological father's presence and number of child's siblings in household, both age 5 years). Family functioning comprised warmth and conflict in the mother-child relationship at age 3 years; ${ }^{40}$ frequency of parent-child joint activities at age 5 years (seven items); and 'household chaos' at age 5 years using a three-item version of the confusion, hubbub and order scale. ${ }^{41}$ Child characteristics measured at age 5 years included researcher-assessed cognitive development (British Ability Scale picture similarities and naming vocabulary scores ${ }^{42}$ ); mother's reports of limiting longterm illness or disability, sleeping difficulties (single item), physical activity (two items) and negative attitudes to school (two items). Lastly, the relevant SDQ score at age 5 years was used to control for prior level of each outcome measure.

\section{Data analysis}

Change in each SDQ scale from ages 5 years to 7 years was regressed separately on screen time using STATA SE12.1 (Stata Corporation, Texas, USA). The survey option took account of the complex survey design and used longitudinal survey weights to compensate for attrition.

Levels of missing information were at less than $2 \%$ of cases for most measures including screen exposure. Exceptions were household income, warmth and conflict scores, and maternal education (7-14\%). The overall percentage of missing data was $27 \%$. In order to decrease bias and increase analytical power, we used multiple chained equations (using the mi package in Stata 12) to impute missing values ${ }^{43}$ separately by gender. Complete case analyses were performed before using imputed data sets. Since the two sets of findings were similar, analyses using the imputed data set are presented here. Estimates were combined across 30 imputed data sets. Cases where the outcome variable was missing $(\mathrm{N}=514,4.7 \%)$ were excluded from analysis (but not imputation) models. ${ }^{43}$ Missing SDQ information was more likely if mothers were from ethnic minorities, less well-educated, not in work and had a less warm relationship with their child.

\section{RESULTS}

At age 5 years, almost two-thirds of children watched TV for between $1 \mathrm{~h}$ and $3 \mathrm{~h}$ daily, with $15 \%$ watching for $\geq 3 \mathrm{~h}$ (table 2). Very few $(<2 \%)$ did not watch any TV. Although TV and games exposure were correlated $(\mathrm{r}=0.20, \mathrm{p}<0.001)$, exposure to games was lower: only $3 \%$ played for $\geq 3$ h daily. As table 2 also shows, boys' levels of TV and games exposure were higher than girls'.

Information on continuous age 7 years adjustment scores are shown in table 3, and abnormal levels of problems defined using recommended cut-offs, indicative of psychiatric diagnoses. $^{44}$ Boys were more likely than girls to show abnormal levels of problems.

Multivariable linear regression models explored associations between screen time and change in each continuous adjustment score from ages 5 years to 7 years. These models provide more sensitive tests of associations between screen exposure and adjustment than logistic analyses using abnormal levels of problems as binary outcomes. Separate models examined the effects of: (a) TV only; (b) electronic games only; and (c) combined screen time. For TV and electronic games, the last three

Table 3 Children's psychosocial adjustment at age 7 years

\begin{tabular}{|c|c|c|c|c|c|}
\hline & $\begin{array}{l}\text { Conduct problems } \\
\text { Mean }(95 \% \mathrm{Cl})\end{array}$ & $\begin{array}{l}\text { Hyperactivity/inattention } \\
\text { Mean }(95 \% \mathrm{Cl})\end{array}$ & $\begin{array}{l}\text { Emotional symptoms } \\
\text { Mean }(95 \% \mathrm{CI})\end{array}$ & $\begin{array}{l}\text { Peer relationship problems } \\
\text { Mean }(95 \% \mathrm{CI})\end{array}$ & $\begin{array}{l}\text { Prosocial behaviour } \\
\text { Mean }(95 \% \mathrm{Cl})\end{array}$ \\
\hline \multicolumn{6}{|l|}{ Boys $(n=5328)$} \\
\hline Mean $(95 \% \mathrm{Cl})$ & 1.55 (1.50 to 1.61$)$ & 3.80 (3.71 to 3.88 ) & 1.47 (1.41 to 1.53$)$ & 1.27 (1.22 to 1.33$)$ & 8.31 (8.26 to 8.37 ) \\
\hline$\%$ with abnormal score & 12.5 & 16.7 & 7.9 & 10.5 & 16.8 \\
\hline \multicolumn{6}{|l|}{ Girls $(n=5172)$} \\
\hline Mean $(95 \% \mathrm{Cl})$ & 2.43 (2.39 to 2.46$)$ & 2.94 (2.85 to 3.02$)$ & 1.38 (1.32 to 1.43$)$ & $1.01(0.96$ to 1.06$)$ & 8.66 (8.62 to 8.71$)$ \\
\hline$\%$ with abnormal score & 7.7 & 8.9 & 6.9 & 7.8 & 7.9 \\
\hline \multicolumn{6}{|l|}{ Total $(n=10500)$} \\
\hline Mean $(95 \% \mathrm{Cl})$ & 2.46 (2.44 to 2.49$)$ & 3.29 (3.23 to 3.36$)$ & 1.33 (1.29 to 1.37$)$ & $1.10(1.06$ to 1.14$)$ & 8.40 (8.36 to 8.43$)$ \\
\hline$\%$ with abnormal score & 10.2 & 12.9 & 7.4 & 9.2 & 12.5 \\
\hline
\end{tabular}


Table 4 Associations between typical daily screen exposure time at 5 years and change in psychosocial adjustment from 5 years to 7 years, adjusting for gender, age and prior adjustment score

\begin{tabular}{|c|c|c|c|c|c|c|c|c|c|c|}
\hline \multicolumn{11}{|l|}{ Imputed dataset, $n=10500$} \\
\hline & \multicolumn{2}{|l|}{ Conduct problems } & \multicolumn{2}{|c|}{ Hyperactivity/inattention } & \multicolumn{2}{|l|}{ Emotional symptoms } & \multicolumn{2}{|c|}{ Peer relationship problems } & \multicolumn{2}{|l|}{ Prosocial behaviour } \\
\hline & Coeff. $(95 \% \mathrm{Cl})$ & $\mathrm{p}$ & Coeff. $(95 \% \mathrm{Cl})$ & $\mathrm{p}$ & Coeff. $(95 \% \mathrm{Cl})$ & $\mathrm{p}$ & Coeff. $(95 \% \mathrm{Cl})$ & $\mathrm{p}$ & Coeff. $(95 \% \mathrm{Cl})$ & $\mathrm{p}$ \\
\hline \multicolumn{11}{|l|}{ Model A) TV/video/DVDs only } \\
\hline \multicolumn{11}{|l|}{ TV/video/DVDs } \\
\hline None & $0.11(-0.09$ to 0.32$)$ & 0.272 & $-0.17(-0.57$ to 0.23$)$ & 0.401 & $-0.06(-0.30$ to 0.19$)$ & 0.640 & $-0.06(-0.25$ to 0.14$)$ & 0.558 & 0.07 (-0.17 to 0.30$)$ & 0.569 \\
\hline$<1 \mathrm{~h}$ & Reference group & & Reference group & & Reference group & & Reference group & & Reference group & \\
\hline 1 to $<3 \mathrm{~h}$ & $0.20(0.12$ to 0.28$)$ & $<0.001$ & $0.05(-0.06$ to 0.17$)$ & 0.354 & $0.07(-0.01$ to 0.15$)$ & 0.075 & $0.06(-0.01$ to 0.12$)$ & 0.094 & $0.05(-0.03$ to 0.12$)$ & 0.201 \\
\hline $3+h$ & $0.50(0.38$ to 0.61$)$ & $<0.001$ & $0.22(0.07$ to 0.36$)$ & 0.004 & $0.18(0.05$ to 0.31$)$ & 0.005 & $0.24(0.13$ to 0.34$)$ & $<0.001$ & $-0.11(-0.22$ to -0.01$)$ & 0.030 \\
\hline \multirow{2}{*}{\multicolumn{11}{|c|}{$\begin{array}{l}\text { Model B) Electronic games only } \\
\text { Electronic games }\end{array}$}} \\
\hline & & & & & & & & & & \\
\hline None & $0.16(0.09$ to 0.24$)$ & $<0.001$ & $0.10(0.00$ to 0.21$)$ & 0.050 & $0.11(0.03$ to 0.19$)$ & 0.008 & $0.00(-0.06$ to 0.07$)$ & 0.919 & $-0.08(-0.16$ to -0.01$)$ & 0.022 \\
\hline$<1 \mathrm{~h}$ & Reference group & & Reference group & & Reference group & & Reference group & & Reference group & \\
\hline 1 to $<3 \mathrm{~h}$ & 0.26 (0.16 to 0.36$)$ & $<0.001$ & $0.03(-0.07$ to 0.14$)$ & 0.525 & $0.12(0.03$ to 0.21$)$ & 0.009 & $0.02(-0.06$ to 0.10$)$ & 0.595 & $-0.04(-0.11$ to 0.04$)$ & 0.378 \\
\hline $3+h$ & $0.52(0.27$ to 0.77$)$ & $<0.001$ & 0.32 (0.02 to 0.62$)$ & 0.036 & 0.38 (0.07 to 0.69$)$ & 0.017 & $0.28(0.06$ to 0.50$)$ & 0.012 & $-0.19(-0.43$ to 0.06$)$ & 0.134 \\
\hline \multicolumn{11}{|c|}{ Model C) Combined screen time (TV/video/DVDs and electronic games) } \\
\hline Neither & $-0.09(-0.38$ to 0.20$)$ & 0.544 & $-0.29(-0.93$ to 0.36$)$ & 0.382 & $-0.07(-0.38$ to 0.25$)$ & 0.680 & $0.11(-0.19$ to 0.41$)$ & 0.481 & $0.07(-0.25$ to 0.40$)$ & 0.662 \\
\hline Both $<1 \mathrm{~h}$, one or both $>$ zero & Reference group & & Reference group & & Reference group & & Reference group & & Reference group & \\
\hline Both $<3 \mathrm{~h}$, one or both $>1 \mathrm{~h}$ & $0.20(0.12$ to 0.28$)$ & $<0.001$ & $0.07(-0.06$ to 0.19$)$ & 0.284 & $0.08(0.00$ to 0.16$)$ & 0.048 & $0.06(0.00$ to 0.13$)$ & 0.060 & $0.05(-0.02$ to 0.13$)$ & 0.143 \\
\hline Either/both for $3+\mathrm{h}$ & 0.51 (0.40 to 0.61$)$ & $<0.001$ & $0.21(0.06$ to 0.36$)$ & 0.006 & $0.22(0.09$ to 0.35$)$ & 0.001 & 0.25 (0.15 to 0.35$)$ & $<0.001$ & $-0.10(-0.20$ to 0.00$)$ & 0.047 \\
\hline
\end{tabular}

Note: Each model was adjusted for the relevant Strengths and Difficulties Questionnaire (SDQ) score at age 5 years, gender and age in months at the age 7 years interview. 
Table 5 Associations between typical daily screen exposure time at 5 years and change in psychosocial adjustment from 5 years to 7 years, with further adjustments for maternal and family characteristics, child characteristics and family functioning

\begin{tabular}{|c|c|c|c|c|c|c|c|c|c|c|}
\hline & \multicolumn{2}{|l|}{ Conduct problems } & \multicolumn{2}{|c|}{ Hyperactivity/inattention } & \multicolumn{2}{|l|}{ Emotional symptoms } & \multicolumn{2}{|c|}{ Peer relationship problems } & \multicolumn{2}{|l|}{ Prosocial behaviour } \\
\hline & Coeff. $(95 \%$ Cl) & $\mathrm{p}$ & Coeff. $(95 \%$ Cl) & $\mathrm{p}$ & Coeff. (95\% Cl) & $\mathrm{p}$ & Coeff. (95\% Cl) & $\mathrm{p}$ & Coeff. $(95 \% \mathrm{Cl})$ & $\mathrm{p}$ \\
\hline \multicolumn{11}{|l|}{ Model A) TV/video/DVDs only } \\
\hline \multicolumn{11}{|l|}{ TV/video/DVDs } \\
\hline None & $0.10(-0.09$ to 0.28$)$ & 0.303 & $-0.21(-0.59$ to 0.17$)$ & 0.274 & $-0.04(-0.28$ to 0.20$)$ & 0.751 & $-0.07(-0.26$ to 0.11$)$ & 0.430 & $0.05(-0.18$ to 0.28$)$ & 0.671 \\
\hline$<1 \mathrm{~h}$ & Reference group & & Reference group & & Reference group & & Reference group & & Reference group & \\
\hline 1 to $<3 \mathrm{~h}$ & 0.07 (0.00 to 0.14$)$ & 0.051 & $0.00(-0.11$ to 0.11$)$ & 0.979 & $0.02(-0.07$ to 0.10$)$ & 0.690 & $0.01(-0.06$ to 0.07$)$ & 0.869 & $0.06(-0.02$ to 0.14$)$ & 0.118 \\
\hline $3+h$ & $0.15(0.05$ to 0.25$)$ & 0.003 & $0.05(-0.09$ to 0.19$)$ & 0.465 & $0.03(-0.10$ to 0.15$)$ & 0.683 & $0.09(-0.01$ to 0.18$)$ & 0.086 & $-0.04(-0.14$ to 0.06$)$ & 0.442 \\
\hline \multicolumn{11}{|l|}{ Model B) Electronic games only } \\
\hline \multicolumn{11}{|l|}{ Electronic games } \\
\hline None & $0.06(-0.01$ to 0.13$)$ & 0.070 & $0.04(-0.06$ to 0.14$)$ & 0.475 & $0.07(-0.01$ to 0.15$)$ & 0.094 & $-0.04(-0.11$ to 0.02$)$ & 0.193 & $-0.05(-0.12$ to 0.03$)$ & 0.206 \\
\hline$<1 \mathrm{~h}$ & Reference group & & Reference group & & Reference group & & Reference group & & Reference group & \\
\hline 1 to $<3 \mathrm{~h}$ & $0.07(-0.02$ to 0.17$)$ & 0.130 & $-0.05(-0.16$ to 0.06$)$ & 0.396 & $0.03(-0.06$ to 0.12$)$ & 0.467 & $-0.06(-0.13$ to 0.02$)$ & 0.133 & $0.00(-0.08$ to 0.08$)$ & 0.989 \\
\hline $3+h$ & $0.19(-0.02$ to 0.40$)$ & 0.075 & $0.16(-0.14$ to 0.46$)$ & 0.300 & $0.26(-0.05$ to 0.57$)$ & 0.106 & $0.15(-0.07$ to 0.37$)$ & 0.194 & $-0.12(-0.36$ to 0.12$)$ & 0.338 \\
\hline \multicolumn{11}{|c|}{ Model C) Different types of screen time (TV/video/DVDs and electronic games) mutually adjusted for one another } \\
\hline \multicolumn{11}{|l|}{ TV/video/DVDs } \\
\hline None & $0.08(-0.10$ to 0.27$)$ & 0.380 & $-0.22(-0.60$ to 0.16$)$ & 0.261 & $-0.05(-0.30$ to 0.19$)$ & 0.660 & $-0.07(-0.25$ to 0.11$)$ & 0.459 & $0.06(-0.17$ to 0.29$)$ & 0.630 \\
\hline$<1 \mathrm{~h}$ & Reference group & & Reference group & & Reference group & & Reference group & & Reference group & \\
\hline $1 \mathrm{~h}$ to $<3 \mathrm{~h}$ & $0.07(0.00$ to 0.14$)$ & 0.048 & $0.01(-0.10$ to 0.12$)$ & 0.900 & $0.02(-0.06$ to 0.10$)$ & 0.637 & $0.01(-0.06$ to 0.08$)$ & 0.813 & $0.06(-0.02$ to 0.13$)$ & 0.146 \\
\hline $3+h$ & $0.13(0.03$ to 0.24$)$ & 0.010 & $0.06(-0.09$ to 0.20$)$ & 0.436 & $0.01(-0.12$ to 0.14$)$ & 0.911 & $0.08(-0.02$ to 0.18$)$ & 0.100 & $-0.04(-0.15$ to 0.06$)$ & 0.436 \\
\hline \multicolumn{11}{|l|}{ Electronic games } \\
\hline None & $0.06(0.00$ to 0.13$)$ & 0.060 & $0.04(-0.06$ to 0.14$)$ & 0.431 & $0.07(-0.01$ to 0.15$)$ & 0.085 & $-0.04(-0.11$ to 0.02$)$ & 0.202 & $-0.04(-0.11$ to 0.03$)$ & 0.232 \\
\hline$<1 \mathrm{~h}$ & Reference group & & Reference group & & Reference group & & Reference group & & Reference group & \\
\hline $1 \mathrm{~h}$ to $<3 \mathrm{~h}$ & $0.06(-0.04$ to 0.15$)$ & 0.231 & $-0.05(-0.16$ to 0.06$)$ & 0.337 & $0.03(-0.06$ to 0.12$)$ & 0.478 & $-0.07(-0.14$ to 0.01$)$ & 0.081 & $0.01(-0.07$ to 0.09$)$ & 0.860 \\
\hline $3+h$ & $0.16(-0.06$ to 0.38$)$ & 0.146 & $0.14(-0.17$ to 0.45$)$ & 0.371 & $0.26(-0.06$ to 0.58$)$ & 0.106 & $0.12(-0.10$ to 0.33$)$ & 0.300 & $-0.08(-0.33$ to 0.16$)$ & 0.503 \\
\hline \multicolumn{11}{|c|}{ Model D) Combined screen time (TV/video/DVDs and electronic games) } \\
\hline Neither & $-0.05(-0.30$ to 0.20$)$ & 0.718 & $-0.30(-0.92$ to 0.31$)$ & 0.330 & $-0.02(-0.32$ to 0.29$)$ & 0.908 & $0.12(-0.16$ to 0.39$)$ & 0.401 & $0.06(-0.26$ to 0.39$)$ & 0.706 \\
\hline Both $<1 \mathrm{~h}$, one or both $>$ zero & Reference group & & Reference group & & Reference group & & Reference group & & Reference group & \\
\hline Both $<3 \mathrm{~h}$, one or both $>1 \mathrm{~h}$ & $0.06(-0.01$ to 0.13$)$ & 0.091 & $0.01(-0.11$ to 0.13$)$ & 0.896 & $0.02(-0.06$ to 0.10$)$ & 0.696 & $0.00(-0.06$ to 0.07$)$ & 0.881 & $0.07(-0.01$ to 0.14$)$ & 0.070 \\
\hline Either/both for $3+\mathrm{h}$ & $0.14(0.05$ to 0.24$)$ & 0.003 & $0.04(-0.10$ to 0.18$)$ & 0.581 & $0.06(-0.07$ to 0.19$)$ & 0.373 & $0.09(0.00$ to 0.18$)$ & 0.061 & $-0.03(-0.13$ to 0.08$)$ & 0.620 \\
\hline
\end{tabular}

Models adjusted for gender, age in months at the age 7 years interview, relevant Strengths and Difficulties Questionnaire (SDQ) score at age 5 years, sociodemographic factors and maternal characteristics (mother's ethnicity, maternal education, equivalised household income, maternal employment, maternal health, biological father's presence and number of child's siblings in household); family functioning (warmth and conflict in the mother-child relationship, frequency of parent-child joint activities and household chaos) and child characteristics (British Ability Scale picture similarities and naming vocabulary scores, limiting long-term illness or disability, sleeping difficulties, physical activity and negative attitudes to school). 
response categories were combined due to small numbers. The reference group was exposure for under an hour daily. For combined screen time, the lack of detailed information necessitated different groupings: $1 \%$ used neither type of screen; $18 \%$ used either or both for less than an hour daily, but neither for an hour or more (reference group); 65\% used either/both types for an hour or more, but neither for three or more hours; and 16\% used either or both for three or more hours.

First, models for screen exposure adjusted for gender, age in months at the 7 years contact and the relevant age 5 years SDQ score (table 4). Exposure to either TV or games for three or more hours was associated with increases in all problems, and (TV only) with reduced prosocial behaviour. Negative effects of exposure for between $1 \mathrm{~h}$ and $3 \mathrm{~h}$ daily were weaker and less consistent. Children playing no games were more likely to show increased problems (except peer problems), compared with playing for $<1 \mathrm{~h}$ daily. Interaction terms for gender $\times \mathrm{TV}$ or gender $\times$ electronic games were added (as appropriate) to these models. None was statistically significant $(\mathrm{p}<0.05)$, suggesting no gender differences in the effect of TV or games on adjustment. Model C (combined screen use) showed similar effects to the model for TV exposure.

The next stage of modelling further adjusted for the full set of covariates relating to maternal and family characteristics; family functioning; and child characteristics (table 5, see note listing covariates in full). All covariates had statistically significant associations $(p<0.05)$ with one or more outcomes in multivariable models (not shown). In models $\mathrm{A}$ and $\mathrm{B}$, TV and games use were each modelled separately. Most associations with adjustment were attenuated to non-significance. The only remaining statistically significant $(p<0.05)$ association was for TV with conduct problems. In Model A (TV modelled without electronic games use), three or more hours' TV predicted a 0.15 point increase in conduct problems. This was reduced only slightly (to 0.13) after adjusting for games use in Model C. In Model D, 3+ hours of either or both types of screen exposure was associated with a 0.14 point increase in conduct problems. This corresponds to 0.09 of a SD increase in age 7 years conduct score (approximate effect size, as age 7 years scores were not normally distributed). For problem scores (conduct, hyperactivity/inattention, emotional and peer relationship), detailed modelling (not shown) indicated that the set of maternal and family characteristics produced the greatest reduction in the effect of screen exposure; followed by adjustment for child characteristics. For prosocial scores, family functioning measures produced the greatest reduction in the effect of screen exposure.

Further adjustment to Models C and D in table 5 for concurrent (age 7 years) TV, electronic games or combined screen use as appropriate did not alter these findings (not shown). No effects of concurrent exposure was statistically significant, with the exception of associations between more than $3 \mathrm{~h} \mathrm{TV}$ or combined screen use at age 7 years and increased hyperactivity (coefficients respectively $0.2195 \%$ CI 0.06 to $0.35, p=0.005$ and $0.1995 \%$ CI 0.05 to $0.33, \mathrm{p}=0.008$ ).

\section{DISCUSSION}

This study found that watching television, videos or DVDs for $3 \mathrm{~h}$ or more daily was associated with a small increase in conduct problems between the ages of 5 years and 7 years, after allowing for other child and family characteristics, including parenting. Findings are in line with other research on younger children aged 2-4 years ${ }^{4}$ and older children ${ }^{5}$ showing associations between TV exposure and aggressive behaviour and bullying; although our study was able to take account of more potential confounders than these other studies. A third longitudinal study, with similar control variables to our own, but with earlier exposure and a longer follow-up, did not find these effects. ${ }^{3}$ We did not find associations between electronic games use and conduct problems, which could reflect the lower exposure to games and/or greater parental restrictions on age-appropriate content for games compared with $\mathrm{TV}^{32}$

Negative findings for other aspects of psychosocial adjustment compared with other studies could be due to a number of reasons, including differences in age group and follow-up period, screen exposure levels, outcome measurement and our more comprehensive set of potential confounders. Contrary to some $^{45}$ but not all other TV studies, ${ }^{3}$ once we had adjusted for other child and family characteristics, we did not find high levels of TV exposure predicted emotional symptoms. This might reflect differences in age group, although TV viewing time in the other studies appears similar. The study with negative findings ${ }^{3}$ most closely resembles our own in terms of adjustment for confounders: studies with positive findings allowed for demographic information only ${ }^{46}$ or a more limited set of family characteristics and functioning. ${ }^{4}$ Unlike several US studies of younger and older children, ${ }^{4} 1011$ we did not find strong evidence for effects of TV or electronic games use on attentional problems. Associations in our study between concurrent TV and increased hyperactivity/inattention may plausibly reflect reverse causation, with active selection of TV by the child. ${ }^{47}$ Although differences in screen time between the US studies and our own were not clear-cut, there are differences in age group and more limited adjustment for confounders in the US studies. Not all research has supported a link between exposure time and attentional problems, ${ }^{25}$ which may be related specifically to non-educational or very early viewing. ${ }^{9}{ }^{48}$ We also did not find clear associations between screen use and peer relationship problems or prosocial behaviour, in contrast to other research on young children. This might reflect different measures: peer relationship problems measured in our own study constitute a broader category than victimisation, associated with TV use in a North American study. ${ }^{3}$ Two studies finding effects of TV on prosocial behaviour ${ }^{4}{ }^{9}$ had different measures and did not adjust for the same range of confounders as our own study. Lastly, and despite finding, in line with other studies, ${ }^{27-31}$ that there were gender differences in psychosocial adjustment and screen use, there was no evidence of differences between boys and girls in the effect of screen use on adjustment.

Limitations of the study include reliance on mothers' reports of adjustment and screen time, but the extent and direction of any effects on our findings are uncertain. Although motherreported screen time has been used in many other population studies, concerns over reliability and validity have not been extensively addressed. ${ }^{49}$ In the UK, there are no guidelines on screen time for young children, unlike US and Australian public health recommendations of less than $2 \mathrm{~h}$ a day. ${ }^{50}$ With the available measures it was not possible to look at the effects of exceeding this limit, although it was possible to examine the $1 \mathrm{~h}$ limit for 3-7-year-olds called for in a recent review. ${ }^{52}$ There was also no information on weekend use, or the content or context of early screen time. Other research has indicated the importance of content for aggression and attentional problems in young children. ${ }^{5} 1448$ Screen time in the context of parental restrictions or discussion of content may moderate negative effects. ${ }^{53}$ However, a recent UK study pointed to limited parental restrictions on age-inappropriate material coupled with high levels of bedroom TV and gaming devices in 5-7-year-olds. ${ }^{32}$

The main strength of this study is that it is the first in the UK to examine longitudinal associations between screen exposure 
and change in psychosocial adjustment. However, further work on data with additional time points is required to establish directional effects and causal mechanisms. Previous UK research in this field has been cross-sectional, with mixed findings. ${ }^{21} 5455$ Other strengths include the use of observational, rather than experimental, data collected from a nationally representative survey. The rich data set allowed for control of many important covariates related to child, maternal and family characteristics and family functioning. ${ }^{215455}$ While direct predictive effects of screen exposure time on adjustment appear to be either small or not found, it remains possible that other effects were mediated by various child characteristics that we controlled for, or were concealed through confounding with, for example, social patterning of screen use.

The study highlights the need for more detailed data to explore risks of various forms of screen time, including exposure to screen violence. In addition, studies should further examine the associated child and family characteristics which appear to account for most of the simple associations between screen exposure and psychosocial adjustment. Our findings do not demonstrate that interventions to reduce screen exposure will improve psychosocial adjustment. Indeed, they suggest that interventions in respect of family and child characteristics, rather than a narrow focus on screen exposure, are more likely to improve outcomes. However, the study suggests that a cautionary approach to the heavy use of screen entertainment in young children is justifiable in terms of potential effects on mental wellbeing, particularly conduct problems, in addition to effects on physical health and academic progress shown elsewhere. $^{3}$

Acknowledgements We would like to thank all of the Millennium Cohort Study families for their cooperation. We are grateful to the Centre for Longitudinal Studies (CLS), Institute of Education for the use of these data and to the Economic and Social Data Service (ESDS) for making them available. The authors thank Geoff Der for statistical advice.

Contributors AP conceived the study, analysed the data and wrote the first draft. HS, DW and MH contributed to the design and interpretation of the findings, and helped revise the article.

Funding This research was funded by the United Kingdom Medical Research Council, grant U130031238. The Millennium Cohort Study is funded by grants to Professor Health Joshi, Director of the study, from the Economic and Social Research Council and a consortium of government funders.

Competing interests None.

Ethics approval South-West, London, Northern and Yorkshire Multi-centre Research Ethics Committees of the NHS.

Provenance and peer review Not commissioned; externally peer reviewed.

Open Access This is an Open Access article distributed in accordance with the Creative Commons Attribution Non Commercial (CC BY-NC 3.0) license, which permits others to distribute, remix, adapt, build upon this work non-commercially, and license their derivative works on different terms, provided the original work is properly cited and the use is non-commercial. See: http://creativecommons.org/ licenses/by-nc/3.0/

\section{REFERENCES}

1 Zimmerman FJ, Christakis DA. Children's television viewing and cognitive outcomes - a longitudinal analysis of national data. Arch Pediatr Adolesc Med 2005;159:619-25

2 Cain N, Gradisar M. Electronic media use and sleep in school-aged children and adolescents: A review. Sleep Med 2010;11:735-42.

3 Pagani LSP, Fitzpatrick CMA, Barnett TAP, et al. Prospective associations between early childhood television exposure and academic, psychosocial, and physical well-being by middle childhood. Arch Pediatr Adolesc Med 2010;164:425-31.

4 Mistry K, Minkovitz C, Strobino D, et al. Children's television exposure and behavioral and social outcomes at 5.5 years: does timing of exposure matter? Pediatrics 2007:120:762-9.
5 Singer MI, Slovak K, Frierson T, et al. Viewing preferences, symptoms of psychological trauma, and violent behaviors among children who watch television. J Am Acad Child Adolesc Psychiatry 1998;37:1041-8.

6 Singer MI, Flannery DJ, Guo SY, et al. Exposure to violence, parental monitoring, and television viewing as contributors to children's psychological trauma. J Community Psychol 2004;32:489-504.

7 Cantor J. The media and children's fears, anxieties, and perception of danger. In: Singer DG, Singer JL, eds. Handbook of children and the media. 2nd edn. Los Angeles: Sage, 2012:215-29.

8 Bickham DS, Rich M. Is television viewing associated with social isolation? Roles of exposure time, viewing context, and violent content. Arch Pediatr Adolesc Med 2006:160:387-92

9 Cheng S, Maeda T, Yoichi S, et al. Early television exposure and children's behavioral and social outcomes at age 30 months. J Epidemiol 2010;20:S482-9.

10 Christakis DA, Zimmerman FJ, DiGiuseppe DL, et al. Early television exposure and subsequent attentional problems in children. Pediatrics 2004;113:708-13.

11 Swing EL, Gentile DA, Anderson CA, et al. Television and video game exposure and the development of attention problems. Pediatrics 2010;126:214-21.

12 Singer JL, Singer DG. Psychologists look at television: cognitive, developmental, personality, and social policy implications. Am Psychol 1983;38:826-34.

13 Vandewater EA, Bickham DS, Lee JH. Time well spent? Relating television use to children's free-time activities. Pediatrics 2006;117:2 e181-e191.

14 Huesmann LR, Moise-Titus J, Podolski C-L, et al. Longitudinal relations between children's exposure to TV violence and their aggressive and violent behavior in young adulthood: 1977-1992. Dev Psychol 2003;39:201-21.

15 Anderson CA, Gentile DA, Dill KE. Prosocial, antisocial and other effects of recreational video games. In: Singer DG, Singer JL, eds. Handbook of children and the media. 2nd edn. Los Angeles: Sage, 2012:249-72.

16 Buckley KE, Anderson CA. A theoretical model of the effects and consequences of playing video games. In: Vorderer P, Bryant J, eds. Playing video games: motives, responses, and consequences. Mahwah, NJ: Erlbaum, 2006:363-78.

17 Colwell J. Needs met through computer game play among adolescents. Pers Individual Differences 2007;43:2072-82.

18 Gentile DA, Choo H, Liau A, et al. Pathological video game use among youths: a two-year longitudinal study. Pediatrics 2011;127:E319-29.

19 Anderson CA, Bushman BJ. Effects of violent video games on aggressive behavior, aggressive cognition, aggressive affect, physiological arousal, and prosocial behavior: a meta-analytic review of the scientific literature. Psychol Sci 2001:12:353-9.

20 Cillero $\mathrm{IH}$, Jago R. Systematic review of correlates of screen-viewing among young children. Prev Med 2010;51:3-10.

21 Hamer M, Stamatakis E, Mishra G. Psychological distress, television viewing, and physical activity in children aged 4 to 12 years. Pediatrics 2009;123:1263-8.

22 Chervin RD, Archbold KH, Dillon JE, et al. Inattention, hyperactivity, and symptoms of sleep-disordered breathing. Pediatrics 2002;109:449-56.

23 Arnold $\mathrm{DH}$. Co-occurrence of externalizing behavior problems and emergent academic difficulties in young high-risk boys: a preliminary evaluation of patterns and mechanisms. J Appl Dev Psychol 1997;18:317-30.

24 Persegani $C$, Russo P, Carucci $C$, et al. Television viewing and personality structure in children. Pers Individual Differences 2002;32:977-90.

25 Stevens T, Mulsow M. There is no meaningful relationship between television exposure and symptoms of attention-deficit/hyperactivity disorder. Pediatrics 2006;117:665-72.

26 Mistry KB, Minkovitz CS, Strobino DM, et al. Children's television exposure and behavioral and social outcomes at 5.5 years: does timing of exposure matter? Pediatrics 2007;120:762-9.

27 Dekker MC, Ferdinand RF, van Lang NDJ, et al. Developmental trajectories of depressive symptoms from early childhood to late adolescence: gender differences and adult outcome. J Child Psychol Psychiatry 2007;48:657-66.

28 Card NA, Stucky BD, Sawalani GM, et al. Direct and indirect aggression during childhood and adolescence: A meta-analytic review of gender differences, intercorrelations, and relations to maladjustment. Child Dev 2008;79:1185-229.

29 Biederman J, Mick E, Faraone SV, et al. Influence of gender on attention deficit hyperactivity disorder in children referred to a psychiatric clinic. Am J Psychiatry 2002;159:36-42.

30 Twenge JM, Nolen-Hoeksema S. Age, gender, race, socioeconomic status, and birth cohort differences on the Children's Depression Inventory: a meta-analysis. J Abnorm Psychol 2002;111:578-88.

31 Cherney ID, London K. Gender-linked differences in the toys, television shows, computer games, and outdoor activities of 5-to 13-year-old children. Sex Roles 2006:54:717-26

32 Ofcom. Children and parents: media use and attitudes report. London: Ofcom, 2011.

33 Hansen $\mathrm{K}$, Johnson J, Joshi $\mathrm{H}$, et al. Millennium Cohort Study first, second, third and fourth surveys: a guide to the datasets. 5th edn. London: Centre for Longitudinal Studies, Institute of Education, University of London, 2010.

34 University of London. Institute of Education. Centre for Longitudinal Studies, Millennium Cohort Study: Third Survey, 2006 [computer file]. 4th Edition. Colchester, Essex: UK Data Archive [distributor], April 2010. SN: 5795, http://dx.doi. org/10.5255/UKDA-SN-5795-1. 
35 University of London. Institute of Education. Centre for Longitudinal Studies, Millennium Cohort Study: Second Survey, 2003-2005 [computer file]. 6th Edition. Colchester, Essex: UK Data Archive [distributor], April 2010. SN: 5350, http://dx.doi. org/10.5255/UKDA-SN-5350-1.

36 University of London. Institute of Education. Centre for Longitudinal Studies, Millennium Cohort Study: First Survey, 2001-2003 [computer file]. 9th Edition. Colchester, Essex: UK Data Archive [distributor], April 2010. SN: 4683, http://dx.doi. org/10.5255/UKDA-SN-4683-1.

37 University of London. Institute of Education. Centre for Longitudinal Studies. Millennium Cohort Study: fourth survey, 2008 [computer file]. First Edition. Colchester, Essex: UK Data Archive [distributor], April 2010. SN:6411.

38 Goodman R. Psychometric properties of the strengths and difficulties questionnaire. J Am Acad Child Adolesc Psychiatry 2001;40:1337-45.

39 Ware J, Kosinski M, Dewey J, et al. How to score and interpret single-item health status measures: a manual for users of the SF-8 health survey. Boston: QualyMetric, 2001

40 Pianta RC. Child-parent relationship scale. Charlottesville, VA: Unpublished measure, University of Virginia, 1992

41 Matheny JAP, Wachs TD, Ludwig JL, et al. Bringing order out of chaos: psychometric characteristics of the confusion, hubbub, and order scale. J Appl Dev Psychol 1995;16:429-44.

42 Elliott CD, Smith P, McCulloch K. British Ability Scales second edition (BAS II): administration and scoring manual. London: NFER-Nelson, 1996.

43 White IR, Royston P, Wood AM. Multiple imputation using chained equations: Issues and guidance for practice. Stati Med 2011;30:377-99.

44 Goodman R. The strengths and difficulties questionnaire: a research note. J Child Psychol Psychiatry 1997;38:581-6.
45 Goodman R, Ford T, Simmons $\mathrm{H}$, et al. Using the Strengths and Difficulties Questionnaire (SDQ) to screen for child psychiatric disorders in a community sample. Br J Psychiatry 2000:177:534-9.

46 Singer M, Slovak K, Frierson T, et al. Viewing preferences, symptoms of psychological trauma, and violent behaviors among children who watch television J Am Acad Child Adolesc Psychiatry 1998;37:1041-8.

47 Bickham DS, Schmidt MH, Huston A. Attention, comprehension and the educational influences of television and other electronic media. In: Singer DG, Singer JL, eds. Handbook of children and the media. Los Angeles: Sage, 2012:113-37.

48 Zimmerman FJ, Christakis DA. Associations between content types of early media exposure and subsequent attentional problems. Pediatrics 2007;120:986-92.

49 Lubans DR, Hesketh K, Cliff DP, et al. A systematic review of the validity and reliability of sedentary behaviour measures used with children and adolescents. Obes Rev 2011:12:781-99.

50 Communications Co, Media. Media education. Pediatrics 2010;126:1012-17.

51 Department of Health and Ageing. Active kids are healthy kids: Australia's physical activity recommendations for 5-12-year-olds. Canberra, Australia: Department of Health and Ageing, 2004.

52 Sigman A. Time for a view on screen time. Arch Dis Child 2012;97:935-42.

53 Nathanson Al. Identifying and explaining the relationship between parental mediation and children's aggression. Commun Res 1999;26:124-43.

54 Griffiths L, Dowda M, Dezateux C, et al. Associations between sport and screen-entertainment with mental health problems in 5-year-old children. Int J Behav Nutr Phys Act 2010;7:30.

55 Page AS, Cooper AR, Griew P, et al. Children's screen viewing is related to psychological difficulties irrespective of physical activity. Pediatrics 2010;126: e1011-17. 